\title{
The Influence of Organizational Silence on Job Burnout: A Practical Study on Shipping Companies in Jordan
}

\author{
Yazan Emnawer Al Haraisa ${ }^{1}$ \\ ${ }^{1}$ Faculty of Business, Tafila Technical University, Jordan \\ Correspondence: Yazan Emnawer Al Haraisa, Faculty of Business, Tafila Technical University, AT-Tafila, P. O. \\ Box 179, Tafila, 66110, Jordan. E-mail: haraisayazan@gmail.com \\ Received: February 17, 2021 \\ Accepted: July 24, 2021 \\ Online Published: August 8, 2021 \\ doi:10.5539/ijbm.v16n10p29 \\ URL: https://doi.org/10.5539/ijbm.v16n10p29
}

\begin{abstract}
The current research aims to identify the influence of organizational silence on job burnout in the shipping companies in Jordan. Therefore, the research population consists of (570) managers, their assistants, and heads of departments in the shipping companies in Jordan .whereas, the research sample consists of (230) employees. The Questionnaires were collected from 207respondents and formed $90 \%$ as a response rate. In addition, the current research used a simple random sample to collect data from respondents. Furthermore, the current research used the Partial Least Square (PLS) technique to test the research hypotheses. The results of the current research reached that the dimensions of organizational silence have a positive impact on job burnout. While the most important recommendation that the shipping companies should adopt the policies and cultures to reduce the job burnout phenomenon by encouraging the employees to speak without any limitations.
\end{abstract}

Keywords: organizational silence, job burnout, shipping companies in Jordan

\section{Introduction}

Organizations currently live in an unstable and unpredictable environment characterized by the presence of a group of constantly changing forces that can constitute a form of pressure on the organization and workers simultaneously. However, organizations need to take their employees' opinions into account (Sholekar \& Shoghi, 2017). More specifically the organization needs employees who are not scared of sharing knowledge and information needed and have the ability to defend their own beliefs and attitudes (Shojaie et al., 2011). On the contrary, the phenomenon of organizational silence, especially the silence of employees in the organization, is not desirable because it refers to the behavior of avoiding employees who expressing the problems or ideas towards the organization development (Demirtaş, 2018). Moreover, the organizations are suffering and complaining from organizational silence because this leads to reduce the effectiveness of organizational decisions and the change process during making employee observations (Paksirat \& Taheri, 2018). Nevertheless, some employees prefer to be silent and do not like to increase their sound and voice and worry about any issue or thing usual within the organization (Fatima et al., 2015).

On the other side, burnout is an infectious phenomenon and this indicates that those affected by fatigue will affect other colleagues very soon (Kheirandish, Farahani \& Nikkhoo, 2016). Consequently, job burnout has been defined as an extended response to long-lasting emotional and personal stressors in the work (Hwa Kwag \& Hee Kim, 2009). Lately, the majority of employees in organizations hurt from a certain level of psychological stress resulting from the nature and conditions of work, and surrounding environmental conditions and how to deal with this level and its departments (Al-Rousan \& Omoush, 2018).

A review of literature exposed that there is a lack of empirical studies on the organizational silence chiefly among employees working at shipping companies in Jordan. Besides, the previous studies such as (Paksirat \& Taheri, 2018; Tahmasebi, Sobhanipour\& Aghaziarati, 2013; Al-Rousan \& Omoush, 2018) measured the impact of organizational silence on job burnout on multiple sectors, while ignoring the sector of shipping companies in Jordan. Accordingly, the purpose of this research is to the know influence of organizational silence on job burnout in the shipping companies in Jordan. 


\section{Literature Review}

\subsection{Organizational Silence}

The term organizational silence is found in organizations that fail to motivate and encourage cooperation, participation, and teamwork, as well as organizations that contain unreliable administrators, which also do not exercise participatory management (Çaylak \& Altuntas, 2017). According to Morrison \& Milliken (2000), they were the first to discuss the concept of organizational silence and defined it as the employee's selection to withhold his or her views or constructive ideas on organizational problems that arise in the organization. While Askari, Sepah and Tawazoe (2015) described organizational silence as the inability of employees to express their views on the organization or keep silent and this will lead to the creation of social events. The term organizational silence refers to the employee's intentionally withholding or blocking information, opinions, ideas, and proposals related to problems facing the organization (Brinsfield, Edwards \& Greenberg, 2009; Vakola \& Bouradas, 2005). According to Ardakani and Mehrabanfar (2015), Organizational silence indicates the absence of effective interaction between employees in the organization and this concept versus the concept of organizational voice. Besides, some researchers see that the organizational silence indicates that workers intentionally withhold or keep some information, opinions, ideas, and proposals related to organizational problems (Brinsfield, Edwards \& Greenberg, 2009; Vakola \& Bouradas, 2005). In another definition, Organizational silence refers to many variables within business organizations, it also indicates preventing or curbing workers from expressing their views and proposals on the development of the organization, and also indicates a lack of interaction with the core issues of the organization's work ( slade,2008 \& nafei,2016). On the other side, the problem of organizational silence begins with hiding the employee's ideas, and then this behavior spreads in all organizations and thus represents a challenge facing organizations (Mengenci, 2015). According to Morrison \& Milliken (2000) Employees are afraid of negative responses from management and the negative thoughts of managers about their employees. These reasons increase the employee's silence in the organization. Moreover, Researchers believe that three factors enhance the behavior of organizational silence, namely the attitude of senior management toward the silence, the supervisor's attitude towards silence, and communication opportunities) Mayhew, Grunwald \& Dey, 2006; Mengenci, 2015).

Additionally, some employees cannot express their opinions openly for several reasons, including that their current location will be affected, and that their suggestions may not make any addition, and they do not trust themselves, or it may be a matter of high risk, in addition to fear of exclusion and harmful relations within the organization (Erigüç et al., 2014). In contrast, the causes of organizational silence can be divided into three groups, for example managerial, organizational, and personality factors (Shojaie, Matin, \& Baranic, 2011). Other researchers mention that two main factors drive employees to adhere to silence, which is the fear by the manager about negative feedback to employees due to the loss of their privileges and jobs, and the employees 'fear of the manager's perceptions towards them (Naghshbandi, Rasekh \& Mohammadhassan, 2017). More specifically, employee silence is a problem for organizations that hinders them towards progress, organizational change, and development processes by preventing information flow to managers in decision-making processes (Tangirala \& Ramanujam, 2008). Besides, the employee's silence can also be defined as the failure to reveal an individual's feelings with trying to hide problems by remaining silent at work as if nothing happened (Yirik et al., 2012).

\subsubsection{Dimensions of Organizational Silence}

There is no agreement among researchers about the dimensions of organizational silence. Some researchers like Van Dyne, Ang, and Botero (2003) divided these into three dimensions as Acknowledge silence, defense-oriented recognition, and silence for the benefit of the organization. Other researchers such as Kahveci and Demirtaş (2013) pointed out that organizational silence consists of five dimensions namely environment of school, emotions, and silence source, isolation and managers. Nafei (2016) mentioned the dimensions of organizational silence such as acquiescent, defensive, pro-social, and protective. While some researchers such as Brinsfield (2009), Akın and Ulusoy (2016) divided the organizational silence of academicians into six dimensions which namely lack self-confidence, protecting relationships with co-workers, acquiescence, self-defense, organizational regulations, and supervisors. Moreover, Abied and Khalil (2019) the dimensions of organizational silence include acquiescent Silence, defensive Silence, and Pro-social Silence. Therefore, the current research will cover the following dimensions:

\subsubsection{Acquiescent Silence}

Abied \& Khalil (2019) described the acquiescent silence as hiding information and ideas as a wish to leave the work or surrender. Acquiescent silence refers to not sharing all of the knowledge, opinions, and feelings about the current situation due to dispensing individuals (Coban \& Sarikaya, 2016). According to Nafei (2016) 
acquiescent silence means blocking related thoughts, information, or views, based on resignation; it also means it is a deliberately silent negative behavior. Moreover, Acquiescent silence refers to employees who are not working basically and they aren't willing to take steps to conduct changes (Pinder \& Harlos, 2001); and they suggest Staffs showing acquiescent silent behavior are not conscious of being of substitute choices to change these circumstances meanwhile they acquiesce in circumstances in their company as it.

\subsubsection{Defensive Silence}

According to Pinder and Harlos (2001), defensive silence is the decision not to speak due to employees' fear of the effects and consequences of expressing their opinions, knowledge, and ideas. Besides, defensive silence is described as a practice in which employees protect themselves from the threats related to articulating their opinions, ideas, and knowledge due to their fear (Van Dyne, Ang, \& Botero, 2003). While Nafei (2016) believes that defensive silence is a deliberate omission of work-related information based on fear of retaliation, it also adds that it is the intended and anticipatory behavior that aims to protect the self from external threats. However, this differentiates defensive silence from acquiescent silence, it is a behavior based on resignation that something cannot change, that speaking out loud will be useless, and therefore unwilling to make any additional efforts to express problems (Wynen et al., 2019).

\subsubsection{Pro-Social Silence}

Pro-social silence refers to preventing or withholding ideas, information, knowledge, and opinions of workers about a situation for the sake of their company and other workers through relying on the foundations or principles of finding cooperation and for the advantage of their co-workers (Van Dyne, Ang, \& Botero, 2003). Pro-social silence also indicates the withholding or preventing of information related to the work of the organization for the advantage of others, involving the organization, and adds that it is intentional and proactive behavior that emphases mainly on others and in the second degree focuses on informed decision-making by the employee (Nafei, 2016). Besides, it is a discretionary or optional behavior that the organization cannot impose (Ighiebemhe, 2019).

\subsection{Job Burnout}

According to Lewig et al. (2007) term of burnout was first used by psychiatrist Herbert Freudenberger in 1974 to describe a specific case of fatigue or exhaustion. Moreover, the problem of burnout is a recurring problem in working life, but it was dealt with as a social problem in the 1970s (Coban \& Sarikaya, 2016). Besides, the Burnout phenomenon happens when there is no harmony and compatibility between the nature of the work and the nature of the person who performs this work (Al-Rousan \& Omoush, 2018). The researchers Maslach \& Jackson (1981) were developed a measure to evaluate job burnout called Maslach Burnout Inventory (MBI). The Burnout phenomenon includes three different dimensions, namely emotional exhaustion, depersonalization, and reduced personal accomplishment (Maslach, Jackson, \& Leiter, 1996). According to Schaufeli \& Enzmann (1998) noted that burnout is one of the most significant elements of employees' happiness, as it might harm workers' health and social relations (Lu \& Gursoy, 2013).

More generally, job burnout leads to reduce emotional sources for individuals; and job burnout is described as a work-related illness caused by stresses related to the workplace and in particular in the jobs of service providers (Gorji, 2011). Job burnout is a long reaction to the enduring emotional and personal stresses on a job, and it's described by its three dimensions namely, cynicism, Feeling ineffective and exhaustion (Maslach, 2003).

It can be said the job burnout refers to negative feelings that the employees suffering caused by the work environment (Wu, Hu \& Zheng, 2019). According to Gupta, Mittal \& Mittal (2018) Job Burnout is observed as a case of bodily, mental and emotional fatigue in employees working in difficult emotional situations. Job burnout is an unpleasant and unsatisfactory condition that affects workers as well as their organization, and their commitment level (Khan et al., 2014). On the other hand, the stage of job burnout model suggests that there are eight stages of burnout and there are three dimensions of burnout, which involve, depersonalization, inefficacy and exhaustion, which are divided into high and low scores (Hwa Kwag \& Hee Kim, 2009).

\subsection{The Organizational Silence and Job Burnout}

In this section, the researcher displays the previous studies that linked organizational silence with job burnout such as (cetin, 2020) found that there is an association between organizational silence and organizational commitment. Abied and Khalil (2019) found in their study there is a significant positive correlation between organizational silence with job burnout and its dimensions. While Farjam et al. (2018) showed there is an effect of occupational burnout on organizational silence. Whereas Al-Rousan and Omoush (2018) study showed there is an effect of organizational silence reasons on burnout. Another study found that there is an inversely 
significant relationship between organizational silence and occupational burnout (Paksirat \& Taheri, 2018). Furthermore, the study of Coban and Sarikaya (2016) found there is no relationship between organizational silence and emotional exhaustion. Conversely, there is a relationship between two dimensions of organizational silence and two dimensions of burnout. Sholekar and Shoghi (2017) showed that there is a significant impact of organizational culture on organizational silence. Akın \& Ulusoy (2016) resulted from there is a positive correlation between organizational silence and levels of burnout. Tahmasebi, Sobhanipour \& Aghaziarati (2013) the study showed there is a positive and strong relationship between organizational silence and burnout.

\subsection{Research Model and Hypothesis}

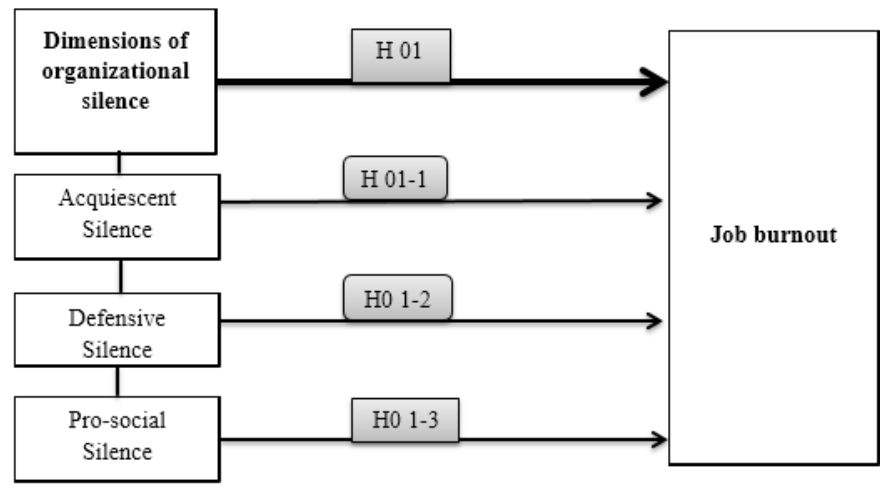

Figure 1. Conceptual model of the research

Source: the proposed model was adopted from the study of (Van Dyne, Ang, \& Botero, 2003; Maslach \& Jackson, 1981) to cover the research variables.

Based on the research problem and objective, the researcher proposed the following hypotheses:

H0- 1: There is no influence of Organizational silence and its dimensions (acquiescent Silence, defensive Silence and Pro-social Silence) on job burnout at the significance level $(\alpha \leq 0.05)$. From the first, the researcher formulated the following sub- Hypotheses

H01-1: there is no influence of acquiescent Silence on job burnout

H01-2: there is no influence of defensive Silence on job burnout

H01-3: there is no influence of Pro-social Silence on job burnout

\section{Methodology}

\subsection{Procedure}

The purpose of this research is to identify the influence of organizational silence on job burnout in the shipping companies in Jordan. Therefore, the current research used Partial Least Square (PLS) technique.

\subsection{Participants}

The number of shipping companies in Jordan (192) according to companies control department (2020). While the research population consists of (570) from the managers, their assistant, deputies and heads of departments in the shipping companies in Jordan. Whereas, the research sample consist of (230) items. Besides, the current research used the simple random sample to collect data from 207 respondents and formed $90 \%$ as a response rate.

\subsection{Measures}

The researcher has used a questionnaire as a tool for gathering the data to analyze it. Also, the questionnaire divided into three parts, the first part covering the personal information and the second part covering the organizational silence and its dimensions adopted from (Van Dyne, Ang, \& Botero, 2003) and the number of questions (15). While the job burnout adopted from (Maslach \& Jackson, 1981) and the number of questions (15). Moreover, the answers of respondents depend on the five Likert scale distributed from (1) strongly disagree to (5) strongly agree. 


\section{Data Analysis}

\subsection{Descriptive Analysis}

The researcher distributed the questionnaire to 230 managers, their assistants and deputies and department heads working in shipping companies in Jordan. Questionnaires were collected from 207 respondents and formed $90 \%$ as a response rate. The following table (1) displays the characteristics of the study sample according to gender, age and Experience and job position.

Table 1 . The characteristics of the study sample

\begin{tabular}{llll}
\hline Variable & Category & Frequency & Percentage (\%) \\
\hline Gender & Male & 173 & 83.6 \\
& Female & 34 & 16.4 \\
Total & & $\mathbf{2 0 7}$ & $\mathbf{1 0 0}$ \\
Experience & Less than (5) years & 104 & 50.2 \\
& (5) to less than (10) years & 52 & 25.1 \\
& (10) to less than (15) years & 32 & 15.5 \\
Total & (15)years and above & 19 & 9.2 \\
Job position & & $\mathbf{2 0 7}$ & $\mathbf{1 0 0}$ \\
& Manager & 45 & 21.7 \\
& Assistant & 29 & 14 \\
& Deputy & 36 & 17.4 \\
Total & Head of department & 97 & 46.9 \\
\hline
\end{tabular}

\subsection{Reliability and Validity of Instrument}

The following table 2 displays the findings of arithmetic means, standard deviations and Convergent validity and Composite analysis results and Cronbach Alpha test and Confirmatory Factor Analysis.

Table 2. Results of arithmetic means, standard deviations and Convergent validity

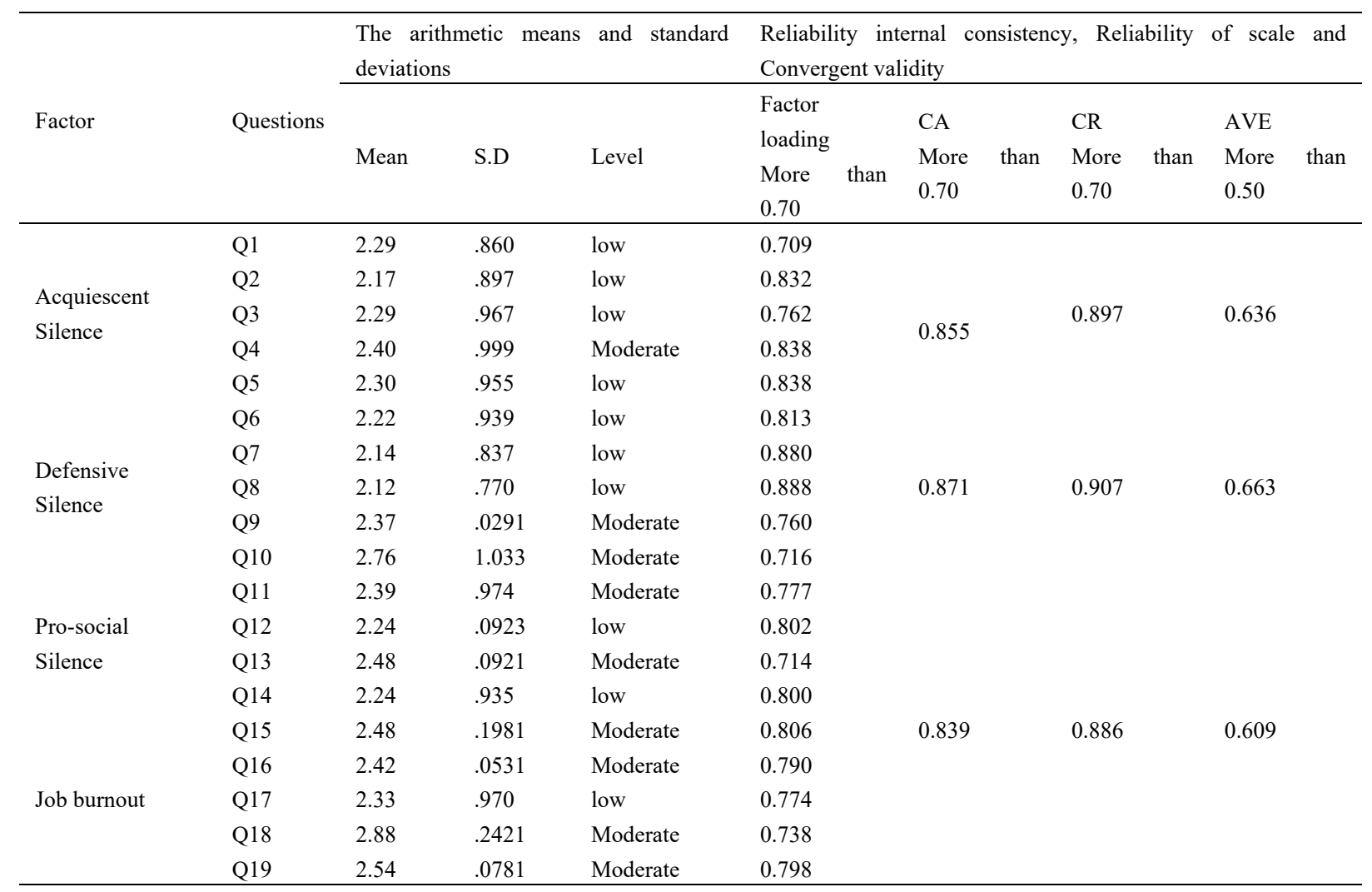




\begin{tabular}{lllllll}
\hline Q20 & 2.43 & .957 & Moderate & 0.787 & & \\
Q21 & 2.65 & .948 & Moderate & 0.798 \\
Q22 & 2.24 & .929 & low & 0.752 & & \\
Q23 & 2.21 & .935 & low & 0.709 & & \\
Q24 & 2.46 & 1.041 & Moderate & 0.725 & & \\
Q25 & 2.59 & .960 & Moderate & 0.724 & 0.531 \\
Q26 & 2.25 & .953 & low & 0.515 & & \\
Q27 & 2.38 & 1.045 & Moderate & 0.788 & & \\
Q28 & 2.33 & .949 & low & 0.734 & \\
Q29 & 2.40 & .847 & Moderate & 0.729 & \\
Q30 & 2.29 & .801 & low & 0.474 & \\
\hline
\end{tabular}

As shown in the table above the value of Cronbach Alpha was (0.855) for the Acquiescent Silence, while the value of Cronbach Alpha was (0.871), whereas the value of Pro-social Silence was (0.839) and the value of Cronbach Alpha was for the job burnout (0.935) which indicates that there is internal consistency among the items of the instrument and all the values of Cronbach Alpha more than 0.70 (Hair et al, 2010). Consequently, the instrument is accepted and valid for analysis. Additionally, the table above shows that all the value of the Composite Reliability is more than (0.70). Accordingly, this refers to that all independent variables are acceptance. While the Average Variance Extracted values more than (0.50) and these values are within the acceptable threshold. Moreover, the factor loading values more than $(0.70)$, and these fall within the acceptable values except paragraph numbers (26) and (30) which were removed in the second level of analysis.

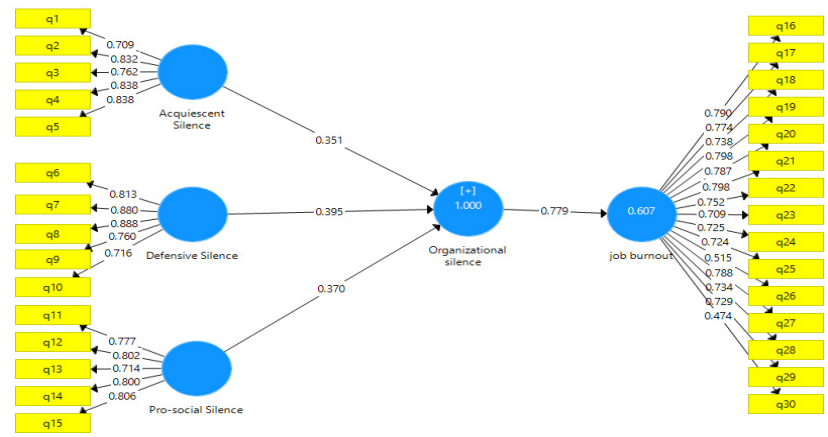

Figure 2. Standardized loading and path coefficient model for the trimmed model

\subsection{Variance Inflation Factor and Tolerance Tests}

Table 3. The results of VIF, tolerance

\begin{tabular}{lll}
\hline Independent Variables & VIF & Tolerance \\
\hline Acquiescent Silence & 2.019 & 0.495 \\
Defensive Silence & 2.492 & 0.401 \\
Pro-social silence & 2.252 & 0.444 \\
\hline
\end{tabular}

Note. Dependent Variable: job burnout.

In the current research, the researcher has been used some tests before conduct the multiple regression analysis such as multicollinearity to ensure that there is no high correlation between the independent variables, as well as, variance inflation factor and tolerance among the independent variables. The following table 4 indicates that the values of variance inflation factor less than 10 and range from (2.019) to (2.492) for all variables. The values of tolerance are higher than 0.05 and range from $(0.401)$ to (0.495). Accordingly, the data subject to a normal distribution (Sekaran \& Bougie, 2013).

\subsection{Research Hypotheses Testing}

To test the hypotheses of the current study, the researcher used Partial Least Square (PLS) technique and the following table 4 to table 7 show the findings of this test. 
Table 4. Result of test the first hypothesis

\begin{tabular}{|c|c|c|c|c|c|c|}
\hline Variables & & $\boldsymbol{\beta}$ & SD & T -test & Sig & Result \\
\hline $\mathrm{R}$ square & & 0.607 & & & & \\
\hline R2 Adjusted & & 0.605 & & & & \\
\hline
\end{tabular}

The table 4 shows that the value of $\mathrm{R}$ (square) (0.607) at a significant level $(0.000)$ which indicates that organizational silence justifies \%60.7 of the change in the job burnout and the value of $\mathrm{T}$ equal (23.278) at a significant level $(\alpha \leq 0.05)$. Furthermore, the value of $\beta(0.779)$ refers that a positive influence of organizational silence on job burnout. Accordingly, we accepted the following hypothesis stated there is a positive influence of organizational silence on job burnout.

Table 5. Result of test the first sub- hypothesis

\begin{tabular}{llllll}
\hline Variables & $\boldsymbol{\beta}$ & SD & T -test & Sig & Result \\
\hline Acquiescent Silence -> job burnout & 0.648 & 0.041 & 15.673 & 0.000 & Accepted \\
R square & 0.420 & & & & \\
R2 Adjusted & 0.417 & & & & \\
\hline
\end{tabular}

The table 5 shows that the value of $\mathrm{R}$ (square) (0.420) at a significant level $(0.000)$ which indicates that acquiescent Silence justifies \%40.2 of the change in the job burnout and the value of $\mathrm{T}$ equal (15.673) at a significant level $(\alpha \leq 0.05)$. Furthermore, the value of $\beta(0.648)$ refers that a positive influence of acquiescent Silence on job burnout. Accordingly, we accepted the following hypothesis stated there is a positive influence of acquiescent Silence on job burnout.

Table 6. Result of test the second sub- hypothesis

\begin{tabular}{llllll}
\hline Variables & $\boldsymbol{\beta}$ & SD & T -test & Sig & Result \\
\hline Defensive & Silence -> job burnout & 0.710 & 0.042 & 16.978 & 0.000 \\
R square & 0.505 & & & & Accepted \\
R2 Adjusted & 0.502 & & & \\
\hline
\end{tabular}

The table 6 shows that the value of $\mathrm{R}$ (square) (0.505) at a significant level $(0.000)$ which indicates that Defensive Silence justifies \%50.5 of the change in the job burnout and the value of $\mathrm{T}$ equal (16.978) at a significant level $(\alpha \leq 0.05)$. Furthermore, the value of $\beta(0.710)$ refers that a positive influence of defensive Silence on job burnout. Accordingly, we accepted the following hypothesis stated there is a positive influence of defensive Silence on job burnout.

Table 7. Result of test the third sub- hypothesis

\begin{tabular}{|c|c|c|c|c|c|}
\hline Variables & $\beta$ & SD & $T$-test & Sig & Result \\
\hline Silence -> job burnout & 0.745 & 0.035 & 21.478 & 0.000 & Accepted \\
\hline R square & 0.555 & & & & \\
\hline R2 Adjusted & 0.553 & & & & \\
\hline
\end{tabular}

The table 6 shows that the value of $\mathrm{R}$ (square) (0.555) at a significant level $(0.000)$ which indicates that Pro-social Silence justifies \%55.5 of the change in the job burnout and the value of $\mathrm{T}$ equal (21.478) at a significant level $(\alpha \leq 0.05)$. Furthermore, the value of $\beta(0.745)$ refers that a positive influence of Pro-social Silence on job burnout. Accordingly, we accepted the following hypothesis stated there is a positive influence of Pro-social Silence on job burnout. 


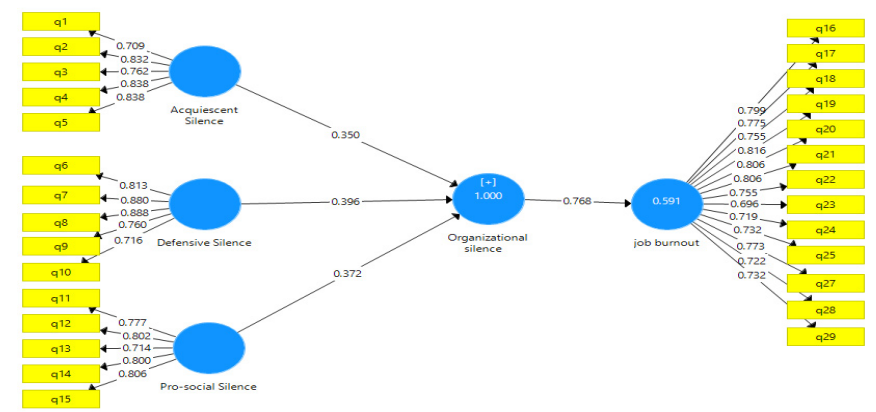

Figure 3. Displays of Standardized Loading and Path Coefficients model for the trimmed Model

\section{Results and Discussions}

The results of current research reached that the dimensions of organizational silence have a positive impact on job burnout, and these results are consistent with what each of such (cetin, 2020) found that there is an association between organizational silence and organizational commitment. Furthermore, Tahmasebi, Sobhanipour and Aghaziarati (2013) indicated that there is a strong relationship between organizational silence and job burnout. Besides, decreasing organizational silence will be reducing staff burnout and this will be lead also to reduce job burnout as a whole and at the same time will lead to enhance job satisfaction and organizational commitment. In addition to these results are aligned with the study of (Abied \& Khalil, 2019) which referred to there is a significant positive correlation between organizational silence with job burnout and its dimensions. As well, the current research agrees with the study of (Akin \& Ulusoy 2016) which reached there is a positive correlation between organizational silence and job burnout. In contrast, the result of current research is not consistent with the studies of (Farjam et al., 2018; Paksirat \& Taheri, 2018) which aim to there is an influence of occupational burnout on organizational silence and there is an inversely significant relationship between organizational silence and occupational burnout. Likewise, we can interpret that occupational or job burnout will make the employees more silent toward the organization's activities and tasks because of the work stress and overload them. Moreover, the study of (Coban \& Sarikaya, 2016) found there is not any relationship between organizational silence and emotional exhaustion as a part of job burnout. The results of the current research can be explained by the fact that organizational silence is a double-edged sword that may have positive effects on the organization if it is optimally utilized and in a manner that achieves the current and future goals of the organization. In contrast, if it used in a negative way and thus leads to leaving the employees the current job and looking for another job in another organization.

\section{Recommendations}

Based on the results of the research, the study presented a set of recommendations, as follows:

1. The shipping companies should adopt the policies and cultures to reduce the job burnout phenomenon by encourage the employees to speak without any limitations.

2. The need to use suitable communication channels among the employees at all the company levels. Besides, the information and knowledge should be available, smooth, and easy to access especially to decision-makers when needed.

3. Encourage and enhance the employees by following empower and delegate strategy and give them autonomy in the workplace to be thinking in new creative and innovative ways.

4. Held the periodical meetings with the employees to know the problems facing them and try to solve them to reduce pressures on the employees and thus perform high performance.

5. Focus on the needs and wants of employees and try to satisfy them whether physically and morally.

\section{Implication and Limitations of the Research}

The results of the current research achievements contribute to managers and researchers being aware of organizational silence; more specifically employee silence. Consequently, the managers in the organization must support their employee's information, ideas and opinion. Besides, this research is limited to shipping companies in Jordan. Furthermore, the current research is based on one specific data collected from one sector; therefore, it is not possible to generalize the results of this research to other sectors. 


\section{Future Prospects}

The researcher proposes a set of proposals as follows:

1. There is a need to conduct future research on another sector such as the telecommunication sector, insurance and banking.

2. Suggest putting a mediating variable for instance work conditions or climate or organizational culture and a control variable such as management policy or compensation strategy.

\section{References}

Abied, E. L. A., \& Khalil, H. M. A. (2019). The impact of Organizational silence on Job Burnout Applied study on doctors and nursing staff at Ain Shams University Hospitals. The Scientific Journal of Business and Environmental Studies, 10(1), 69-104. https://doi.org/10.21608/jces.2019.50913

Akın, U., \& Ulusoy, T. (2016). The Relationship between Organizational Silence and Burnout among Academicians: A Research on Universities in Turkey. International Journal of Higher Education, 5(2), 46-58. https://doi.org/10.5430/ijhe.v5n2p46v

Al-Rousan, M. A. M., \& Omoush, M. M. (2018). The Effect of Organizational Silence on Burnout: A Field Study on Workers at Jordanian Five Star Hotels. Journal of Management and Strategy, 9(3), 114-122. https://doi.org/10.5430/jms.v9n3p114

Ardakani, M. A., \& Mehrabanfar, E. (2015). Organizational Silence, from Roots to Solutions: A Case Study in Iran Petroleum Industry. Iranian Journal of Oil and Gas Science and Technology, 4(2), 68-83.

Askari, R., Sepah, F., \& Tawazoe, Z. (2015). Study of the relationship between organizational silence and organizational performance among staff of educational hospitals of Sadouqi medical science university. Research-science Journal of Yazd School of Health, (3), 15.

Brinsfield, C. T., Edwards, M. E., \& Greenberg, J. (2009). Voice and Silence in Organizations: Historical review and current conceptualizations. Emerald Group Publishing Limited.

Çaylak, E., \& Altuntas, S. (2017). Organizational Silence Among Nurses: The Impact on Organizational Cynicism and Intention to Leave Work. The Journal of Nursing Research, 25(2). 90-98. https://doi.org/10.1097/jnr.0000000000000139

Cetin, A. (2020). Organizational Silence and Organizational Commitment: A Study of Turkish Sport Managers. Annals of Applied Sport Science, 8(2), e830.

Coban, H., \& Sarikaya, M. (2016). A Research on the Relationship between Organizational Silence and Burnout. European scientific Journal, 145- 154.

Companies Control Department. (2020). Retrieved from http://www.ccd.gov.jo/bylink12.aspx

Demirtaşi, Z. (2018). The relationships between organizational values, job satisfaction, organizational silence and affective commitment. European Journal of Education Studies, 4(11), 108-125.

Erigüç, G., Ozer, O., Turac, I. S., \& Songur, C. (2014). Organizational silence among Nurses: A Study of structural equation modeling. International Journal of Business, Humanities and Technology, 1(4), 150-162.

Farjam, S., Almodarresi, S. M. A., Pirvali, E., Saberi, H., \& Malekpour, S. (2018). The mediator effect of occupational burnout on the relationship between organizational cynicism and organizational silence: Case of study: Employees of Farokhshahr social security organization hospital.

Fatima, A., Salah-Ud-Din, S., Shanza, K., Misbah, H., \& Hammad, A. H. (2015). Impact of Organizational Silence on Organizational Citizenship Behavior: Moderating Role of Procedural Justice. Journal of Economics, Business and Management, 3(9), 846-850. https://doi.org/10.7763/JOEBM.2015.V3.296

Gorji, M. (2011). The Effect of Job Burnout Dimension on Employees' Performance. International Journal of Social Science and Humanity, 1(4), 243-246. https://doi.org/10.7763/ijssh.2011.v1.43

Guangdong, W., Zhibin, H., \& Junwei, Z. (2019). Role Stress, Job Burnout, and Job Performance in Construction Project Managers: The Moderating Role of Career Calling. International Journal of Environment Research and Public Health, 16(13). https://doi.org/10.3390/ijerph16132394

Gupta, B., Mittal, S., \& Mittal, V. (2018). Analyzing the impact of job burnout on job satisfaction - a study on Indian bank employees. Towards Excellence: An Indexed Refereed Journal of Higher Education, 10, 19-30.

Hair, J., Black, W., Babin, B., \& Anderson, R. (2010). Multivariate Data Analysis: A global Perspective (7th ed.). 
Pearson Education, Inc., Saddle River, New Jerry.

Ighiebemhe, O. A. (2019). Employee silence and its effects on organizational effectiveness. International Journal of Indian Economic Light, 7, 56-61.

Kahveci, G., \& Demirtaş, Z. (2013). Development study of organizational silence scale for teachers. Electronic Journal of Social Sciences, 12(43), 167-182.

Khan, F., Rasli, A. M., Yusoff, R. M., Faizan Malik, M., Muddassar, K. M., \& Khan, Q. (2014). Effect of emotional exhaustion on organizational commitment among academicians. Science International, 26(5), 2433-2437.

Kheirandish, M., Farahani, A., \& Nikkhoo, B. (2016). The impact of Organizational Culture on employees' Job Burnout, International Academic Journal of Organizational Behavior and Human Resource Management, $3(10), 1-15$.

Kwag, S. H., \& Kim, M. H. (2009). The Study on the Effects of Organizational Members' Job Burnout. Journal of Business and Economics Research,7(7), 63-78. https://doi.org/10.19030/jber.v7i7.2315

Lewig, K. A., Xanthopoulou, D., Bakker, A. B., Dollard, M. F., \& Metzer, J. C. (2007). Burnout and connectedness among Australian volunteers: A test of the Job Demands-Resources model. Journal of Vocational Behavior, 71, 429-445. https://doi.org/10.1016/j.jvb.2007.07.003

Lu, A. C. C., \& Gursoy, D. (2013). Impact of Job Burnout on Satisfaction and Turnover Intention: Do Generational Differences Matter? Journal of Hospitality and Tourism Research, 40(2), 1-26 https://doi.org/10.1177/1096348013495696

Maslach, C., \& Jackson, S. (1981). The measurement of experience burnout. Journal of Occupational and Behavioral Science, 2, 99-113. https://doi.org/10.1002/job.4030020205

Maslach, C., Jackson, S. E., \& Leiter, M. P. (1996). Maslach Burnout Inventory Manual (3rd ed.). Palo Alto, CA: Consulting Psychologists Press.

Mayhew, M. J., Grunwald, H. E., \& Dey, E. L. (2006). Breaking the silence: Achieving a positive climate for diversity from the staff perspective. Research in Higher Education, 47(1), 63-88. http://dx.doi.org/10.1007/s11162-004-8152-z

Mengenci, C. (2015). Antecedents and Consequences of Organizational Fear and Silence Behavior: Evidence Service Sector from Turkey. International Business Research, 8(5), 223-229. https://doi.org/10.5539/ibr.v8n5p223

Morrison, E. W., \& Milliken, F. J. (2000). Organizational silence: A barrier to change and development in a pluralistic world. Academy of Management Review, 25(4), 706-725. https://doi.org/10.5465/amr.2000.3707697

Nafei, W. A. (2016). Organizational Silence: Its Destroying Role of Organizational Citizenship Behavior. International Business Research, 9(5), 57-75. https://doi.org/10.5539/ibr.v9n5p57

Naghshbandi, S., Rasekh, N., \& Mohammadhassan, F. (2017). Validating Organizational Silence Questionnaire at Ministry of Youth Affairs and Sports of Iran. International Journal of Social Sciences, 7(3), 51-57.

Paksirat, V., \& Taheri, A. (2018). Organizational Silence and Occupational Burnout with Job Performance. Journal of System Management, 4(4), 039-050.

Pinder, C., \& Harlos, H. (2001). Employee Silence: Quiescence and Acquiescence as Response to Perceived Injustice. Research in Personnel and Human Research Management, 20, 331-369. http://dx.doi.org/10.1016/S0742-7301(01)20007-3.

Schaufeli, W., \& Enzmann, D. (1998). The burnout companion to study and practice: A critical analysis. Boca Raton. FL: CRC Press.

Sekaran, U., \& Bougie, R. (2013). Research Methods for Business: A Skill-Building Approach (6th ed.). Wiley, New York.

Shojaiea, S., Matin, H. Z., \& Baranic, G. (2011). Analyzing the Infrastructures of Organizational Silence and Ways to Get Rid of it. Procedia - Social and Behavioral Sciences, 30, 1731-1735. https://doi.org/10.1016/j.sbspro.2011.10.334

Sholekar, S., \& Shoghi, B. (2017). The Impact of Organizational Culture on Organizational Silence and Voice of Faculty Members of Islamic Azad University in Tehran. Iranian Journal of Management Studies (IJMS), 
10(1), 113-142. https://journals.ut.ac.ir/article_60720_3700ef5c0c23555b3cfb80d582fc92d2.pdf

Slade, M. (2008). The adaptive nature of organizational silence: A cybernetic exploration of the hidden factory. George Washington University.

Tahmasebi, F., Sobhanipour, S. M., \& Aghaziarati, M. (2013). Burnout; Explaining the Role of organizational silence and its influence (case study: selected executive organizations of Qom province). Journal of Basic and Applied Scientific Research, 3(8), 272-282.

Tangirala, S., \& Ramanujam, R. (2008). Employee Silence on Critical Work Issues: The Cross Level Effects of $\begin{array}{lllll}\text { Procedural Justice } & \text { Climate. Personnel }\end{array}$ https://doi.org/10.1111/j.1744-6570.2008.00105.x

Vakola, M., \& Bouradas, D. (2005) Antecedents and consequences of organisational silence: an empirical investigation. Employee Relations, 27(5), 441-458. https://doi.org/10.1108/01425450510611997

Van Dyne, L., Ang, S., \& Botero, I. C. (2003). Conceptualizing employee silence and employee voice as multidimensional constructs, Journal of Management Studies, 40(6), 1359-1392. https://doi.org/10.1111/1467-6486.00384

Wynen, J. K., Bjorn, V., Koen, L., \& Rolland, V. (2019). Just keep silent... Defensive silence as a reaction to successive structural reforms. Journal Public Management Review, https://doi.org/10.1080/14719037.2019.1588358

Yirik, Ş., Yilmaz, Y. D., Osman, N., Yilmaz, Y., Akgün, A., \& Kinay, H. (2012). Analysis of the hotel personnel's conceptions of organizational justice, organizational silence, mobbing, organizational commitment in terms of demographic variables. 3rd International Symposium on Sustainable Development, 82-94.

\section{Copyrights}

Copyright for this article is retained by the author(s), with first publication rights granted to the journal.

This is an open-access article distributed under the terms and conditions of the Creative Commons Attribution license (http://creativecommons.org/licenses/by/4.0/). 